\title{
Do prazer ao pensamento crítico em Harry Potter
}

Milena de Azeredo Pacheco Venancio

Mestra pelo Programa de Pós-Graduação em Mídia e Cotidiano, Departamento de Comunicação Social da Universidade Federal Fluminense

E-mail: milena.pacheco@gmail.com

Alexandre Farbiarz

Docente do Programa de Pós-Graduação em Mídia e Cotidiano, Departamento de Comunicação Social da Universidade Federal Fluminense

E-mail: alexandre.farbiarz@gmail.com

Resumo: A proposta deste artigo é discutir a construção de um pensamento crítico em jovens através da difusão de narrativas elaboradas por fãs de cultura pop. Serão considerados para análise fanfics e memes sobre política e sociedade que se encontram na Internet e estão ligados à obra Harry Potter, em articulação com estudos sobre educação, letramento midiático e cultura.

Palavras-chave: educação; Harry Potter; memes; fanfics.
Abstract: The purpose of this article is to discuss the developing of critical thinking in young people through the dissemination of narratives created by pop culture fans. Fanfics in general and memes on politics and society, found on the Internet and associated with fantasy novel series Harry Potter, were considered for the analysis. This discussion is articulated with studies on education, media literacy and culture.

Keywords: education; Harry Potter; memes; fanfics.

\section{INTRODUÇÃO}

Com o advento da internet, é cada vez mais comum a expansão de universos ficcionais por leitores a partir de novas perspectivas das narrativas e personagens do enredo, através de fanfics $^{1}$ e memes $^{2}$, por exemplo.

Tais formas de uso das obras ficcionais estabeleceram novos meios de construção crítica, a partir de um conjunto de práticas que denotam a capacidade de uso de diferentes materiais em diversos gêneros e mídias, para a discussão de variados temas. Assim, o público, que também é consumidor, passa a utilizar as novas tecnologias para se envolver com as mídias tradicionais, "encarando a Internet como um veículo para ações coletivas - solução de problemas, deliberação pública e criatividade alternativa"'.

Em fanfics e memes, várias vezes há abertura à discussão de questões de interesse coletivo, como o debate sobre formas de preconceito e apoio a

Recebido: 07/12/2016 Aprovado: 30/06/2017

1. Fanfic (fanfiction, ou mesmo fic) é uma narrativa de ficção criada por fãs com a intenção de estabelecer narrativa paralela à história original.

2. Imagem, vídeo ou texto que, geralmente, utiliza humor para fazer referência a tema ou situações inusitadas que se espaIham rapidamente pela Internet.

3. JENKINS, Henry. Cultura da convergência. 2. ed. São Paulo: Aleph, 2009, p. 235. 
4. Idem, p. 237.

5. JENKINS, Henry. Lendo criticamente e lendo criativamente. Matrizes, São Paulo, a. 6, n. 1, jul./dez. 2012. p. 11-24. Disponível em: <http://www.revistas. usp.br/matrizes/article/ download/ 48047/51801>. Acesso em: 22 jan. 2016.

6. SODRÉ, Muniz. Antropológica do espelho: uma teoria da comunicação linear e em rede. Petrópolis: Vozes, 2013.

7. SÁ, Simone. Fanfictions, comunidades virtuais e cultura das interfaces. Anais do XXV Congresso Brasileiro de Ciências da Comunicação, Salvador, 1 a 5 de setembro de 2002. Disponível em: <http://www. intercom.org.br/papers/ nacionais/2002/Congresso2002_Anais/2002_NP8SA.pdf> Acesso em 21 mar. 2017.

8. Idem, ibídem.

9. Quando da elaboração deste artigo, a página "Hogwarts vai virar Cuba" estava ativa no Facebook, porém, foi deletada recentemente. Alguns arquivos se encontram em publicações de outras páginas afins. Além disso, quando começou a fazer sucesso, foram publicadas matérias sobre a fanpage, o que também preserva alguns arquivos. No site HuffPost Brasil, por exemplo, foi publicada uma matéria em maio de 2015. Disponível em: <http://www.brasilpost.com.br/2015/05/04/ hogwarts-vai-virar-cuba-p n 7204610.html>. Acesso em: 24 out. 2016. movimentos sociais. Um exemplo está nas discussões incitadas pela série Harry Potter, que trata "muito explicitamente com questões de Educação (muitas vezes dando voz aos direitos das crianças, em detrimento de restrições institucionais" ${ }^{\text {) }}$ ).

Assim, quando os fãs dão continuidade a determinadas histórias, além da curiosidade por questões que o enredo desperta, mas não responde, há o desejo de dar sequência à narrativa ${ }^{5}$. A criação de fanfics e memes se dá, assim, por uma necessidade provocada pelo prazer do contato com a obra, bem como pelo interesse em discutir, sob o próprio ponto de vista, questões apresentadas na história. Nesse sentido, então, há um potencial educativo para o público. Afinal, educar é causar um estranhamento no indivíduo que o leve à possibilidade de pensar sobre algo ${ }^{6}$.

Entretanto, ao se aproximar entretenimento e educação, propondo possibilidades de discussão de pautas sociais a partir de produtos midiáticos, há de se considerar, também, desigualdades no acesso às diferentes mídias, bem como as características que definem o interesse em prolongar determinada história através de novas narrativas.

Assim sendo, propõe-se, com este artigo, discutir possibilidades de construção de um pensamento crítico em jovens através da difusão de narrativas de fanfics e memes. A partir disso, busca-se fazer uma análise crítica das relações de aproximação entre produtos da indústria cultural como Harry Potter e a educação.

\section{UMA VISÃO SOBRE FANFICS E MEMES}

Um detalhe importante para compreender o sucesso de narrativas como fanfics e memes está no fato de que, segundo os fãs, essas narrativas se relacionam com sua visão particular de mundo ${ }^{7}$. Logo, histórias de ficção como as de Harry Potter podem contribuir para desenvolver um pensamento crítico nos fãs, uma vez que lhes inspiram a participação, com opiniões, em variados temas abordados na produção das próprias narrativas. Essa forma de lidar com a mídia auxilia a desenvolver diferentes habilidades nos jovens ${ }^{8}$. Permite que, por meio da ficção, eles reflitam sobre questões do cotidiano, especialmente aquelas com as quais se identificam.

A empatia causada pelo fato de os personagens e a estrutura narrativa amadurecerem à medida que os livros e filmes avançam, acompanhando o amadurecimento do público-alvo, favorece a identificação, além de a narrativa se passar em ambiente escolar. Nesse sentido, a obra permite que os jovens relacionem o enredo com suas experiências representadas na série: preocupações com os estudos, hierarquia escolar, relações com amigos e diferentes professores - ora queridos, ora questionados, ora antipáticos.

Na página "Hogwarts vai virar Cuba" , as construções narrativas giravam em torno de uma suposta Escola de Magia e Bruxaria de Hogwarts socialista. Assim, através de memes, reproduziam reflexões sobre o cotidiano, influenciando a discussão política entre os jovens que seguiam a página. 


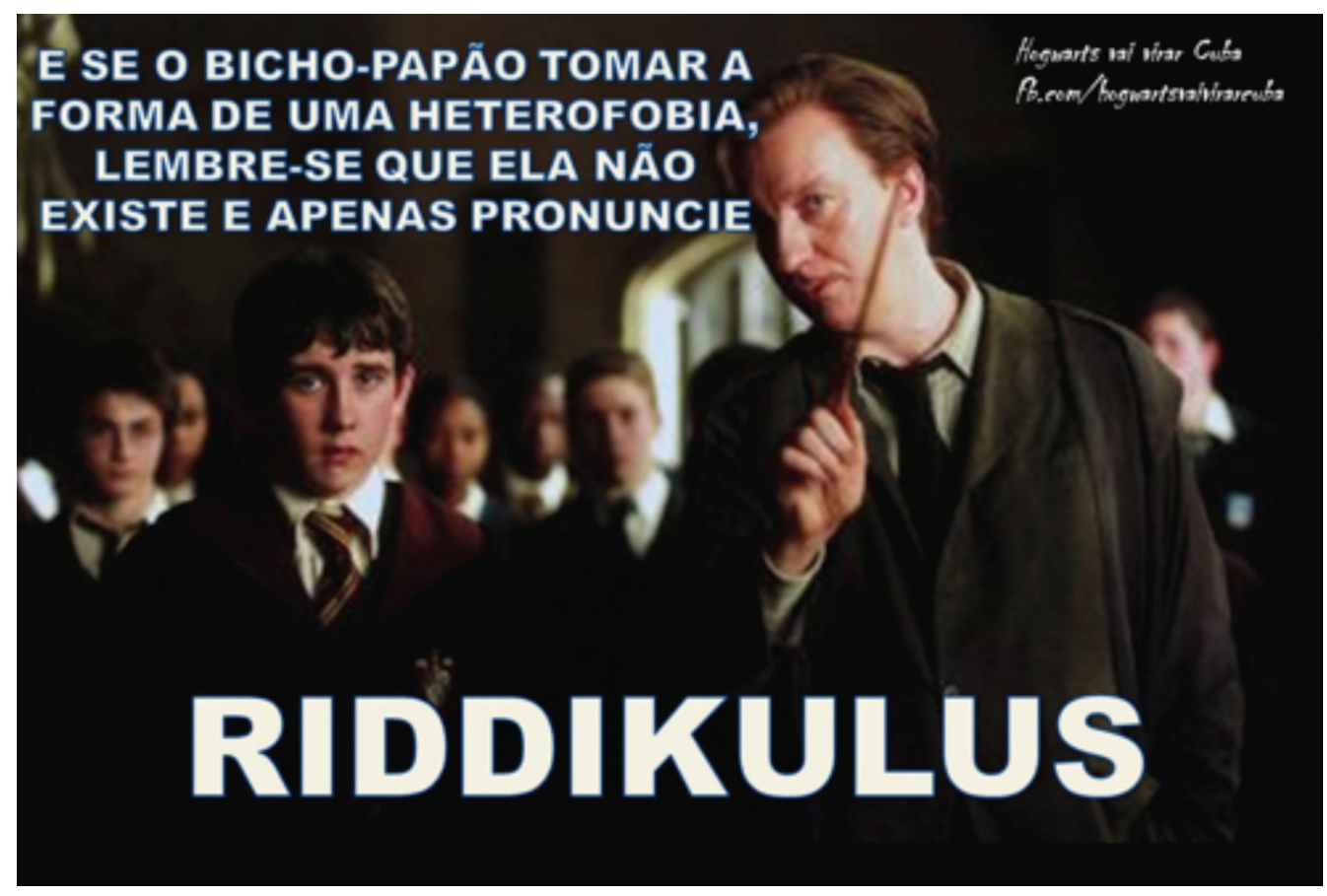

Figura 1: Em postagem de 25 de janeiro de 2016, o professor Remo Lupin ensina sua "Defesa contra a arte das trevas" ao aluno Neville Longbottom.

O professor na imagem dá aula aos alunos da Escola de Magia e Bruxaria de Hogwarts, na disciplina "Defesa contra as artes das trevas". Na cena reproduzida no meme, o professor utiliza o exemplo de um bicho-papão ${ }^{10}$ para que os alunos treinem a execução do feitiço patrono, no qual a forma prateada de um animal se materializa, protegendo os bruxos bons das ações de vilões e outras criaturas más.

No caso do meme, o ser "das trevas" é a "heterofobia", em uma crítica ao termo popularizado pela parcela homofóbica da sociedade, que busca inverter a relação de preconceito que os homossexuais ${ }^{11}$ sofrem constantemente, como se estes fossem privilegiados e preconceituosos em relação aos héteros.

De modo a enfatizar a descrença nessa linha de raciocínio, é dito no meme que a heterofobia não existe, e o aluno deve chamá-la de ridícula, associando-a a um feitiço com o nome de "riddikulus", que se assemelha a outros nomes de feitiços criados pela autora de Harry Potter $^{12}$.

Um fator importante no contato com os memes é a complementaridade entre imagens e textos. A utilização de cenas dos filmes remetia àquele momento narrativo e a outras cenas ou personagens relacionadas à situação apresentada, pois, assim, as referências no texto se tornavam mais claras. No exemplo da Figura 1, não é necessário contextualizar para os fãs que se trata de uma cena em que aparece um bicho-papão e são treinados feitiços, pois isso já é transmitido pela imagem. Foram unidas, portanto, características de diferentes contextos para propiciar uma reflexão sobre a problemática do preconceito, de modo a impactar, através de uma nova narrativa, os fãs da série.

10. Na história de Harry Potter o bicho-papão é um ser real, capaz de se transformar naquilo que a pessoa que o confronte mais tema.

11. Embora haja uma discussão acerca do uso do termo "homossexual", muitas vezes sendo sugerido o termo "homoafetivo" em seu lugar, não se entrará nessa questão, uma vez que isso demandaria outros estudos paralelos, o que não é o foco deste artigo. Será mantido, portanto, o uso da palavra "homossexual" neste texto, considerando-a equivalente a "homoafetivo".

12. Muitos feitiços em Harry Potter fazem referência a palavras em latim, sendo alguns de sonoridade parecida com a da palavra utilizada no meme. Ver "O que significam, em latim, os feitiços de Harry Potter". Disponível em: <http:// super.abril.com.br/ cultura/o-que-significam-em-latim-os-feiticos-de-harry-potter/>. Acesso em: 18 maio 2017. 
13. Movimento criado em 2004 e definido pelo objetivo de combater uma "doutrinação marxista" que, segundo os representantes do movimento, existe nas escolas. Dispo nível em: <http://www. escolasempartido.org/> Acesso em: 10 ago. 2016

14. Escola de Magia e Bruxaria de Hogwarts: instituição em que Harry estuda e onde conhece seus melhores amigos. É dividida em quatro casas que abrigam, cada uma, um grupo de alunos: Corvinal, Grifinória, Lufa-lufa e Sonserina, nomes dados em homenagem aos sobrenomes de cada bruxo fundador da escola. As casas disputam entre si o campeonato de quadribol ao longo do ano.

15. Lord Voldemort: principal vilão da história. Tem um plano de poder que busca eliminar todos aqueles que não são bruxos de sangue puro. Seu nome verdadeiro é Tom Riddle.

16. Hermione Granger: uma das melhores alunas da Escola de Magia e Bruxaria de Hogwarts. É esperta e exigente, além de ser a melhor amiga de Harry. É uma das personagens que sofre mais preconceito na história, por não ser considerada de "sangue puro".

17. Postagem de usuário reproduzida na página Quebrando o tabu em 27 de outubro de 2015. Disponível em: $<$ https://pt-br.facebook. com/quebrandootabu/ posts/981735851882802>

Acesso em: 10 ago. 2016.

18. PUGH, Sheenagh. The democratic genre: fan fiction in a literary context. Londres: Seren 2006.

19. JENKINS, Henry. Cultura da convergência. 2. ed. São Paulo: Aleph, 2009, p. 248-249.
Em outro momento, partindo da falácia de "doutrinação de esquerda" nas escolas brasileiras, criada com o Movimento Escola Sem Partido ${ }^{13}$, um fã de Harry Potter fez uma analogia em postagens no Facebook que comparavam a proposta do movimento com características de personagens e momentos do enredo, criando um texto com características de fanfic.

Hogwarts $^{14}$ 2015:

- Bom dia alunos, hoje vamos estudar História da Magia Contemporânea. Podem abrir os livros ai na página 314.

- ... Professor, "queda de Voldemort ${ }^{15}$ ?"

- Isso, hoje vamos estudar como Harry Potter derrotou Voldemort.

- Ih... Já vi que esse "professor" é Pottista.

- Como é?

- É, Pottista, fica ai fantasiando como o mundo com "Potter" é melhor.

- Não criança, eu vivi o tempo da guerra, falaremos só sobre fatos.

- Pff... fatos... fatos contados pela esquerda potista né?

- Esquerda potista?

- É, esses loucos que se vestem de vermelho fazendo alusão a Grifinória. Deviam ser presos.

- Presos? Por quê? O Potter salvou o mundo mágico, derrotou junto com seus amigos a ameaça de Voldemort...

- Salvou?? Depois que a Hermione ${ }^{16}$ libertou os elfos domésticos, sabe quanto custa manter um em casa, com esses direitos trabalhistas? Um absurdo...

- É, mas antes o que os bruxos faziam era escravidão, sem nenhuma consideração com os elfos!

- Nah... antigamente era melhor... vou começar a fazer uma campanha... "Volta Voldemort".

- Pois você acaba de perder 15 pontos para sua casa.

- VOCÊ ESTÁ DOUTRINANDO OS ALUNOS? MEU PAI NÃO ACEITA QUE ESSES PROFESSORES POTTISTAS FAÇAM DOUTRINAÇÃO EM SALA DE AULA!

- Menos 20 pontos.

Qualquer semelhança com a realidade é mera coincidência. ${ }^{17}$

No segundo exemplo, que não é acompanhado de imagens, houve a criação de uma nova narrativa sobre política brasileira, com referências à série Harry Potter. O autor parte da ideia de que os leitores compreenderiam a ficção ali criada a partir de seu conhecimento da história dos livros e filmes.

Tal apropriação aplica as habilidades necessárias para que o jovem discuta assuntos que muitas vezes aparecem de forma bem mais sutil na história original. Segundo $\mathrm{Pugh}^{18}$, as criações dos fãs nas fanfics, de modo geral, se relacionam a duas questões básicas, também interligadas: "E se?" e "O que mais?".

Assim, fanfics e memes são construções narrativas formadoras de letramento midiático, uma vez que se considerem as competências de expressar interpretações e sentimentos em relação a ficções populares, por meio de sua própria cultura tradicional, e de distribuir e compartilhar criações através da Internet, reproduzindo a história de Harry Potter em um novo contexto ${ }^{19}$. 
Ora, se a narrativa, que situa o indivíduo no mundo, é o que articula a experiência humana ${ }^{20}$, há um caminho seguido pelo leitor desde o contato com o texto até a influência que este passa a exercer, levando aquele à ampliação da narrativa. Seu mundo e o do texto se cruzam, tornando a história contada algo em comum, que direciona suas atitudes a partir daquele momento.

\section{EFEITOS E POSSIBILIDADES DE PENSAMENTO CRÍTICO NA DIFUSÃO DE FANFICS E MEMES}

Nylund $^{21}$, à luz de Miller ${ }^{22}$, afirma que a cultura da mídia contribui para que os indivíduos formem suas identidades de acordo com valores hegemônicos. Considerando tal perspectiva, se por um lado Harry Potter é uma obra que abre possibilidades para o público desenvolver um pensamento crítico, por outro, é objeto próprio dessa cultura midiática.

Acrescente-se a isso o papel da indústria cultural ${ }^{23}$, que tende a desqualificar o conhecimento, idolatrando somente o prazer em suas manifestações mercadológicas ${ }^{24}$. Nesse contexto, a mídia ocupa lugar essencial. Embora os primeiros livros da coleção Harry Potter não tenham sido lançados dentro de uma maior estrutura comercial, o que já não é próprio ao mercado editorial, muito mudou quando a obra virou best-seller e chegou ao cinema, levando consigo vários produtos para consumo dos fãs. Esse consumo, pode-se dizer, também é provocado pela necessidade que o público tem de manter contato com a narrativa, transformando-a em mercadoria. Embora não se possa atribuir a esse aspecto uma relação de dominação, de fato atua sobre o gosto do público pela obra. Afinal, de acordo com o pensamento de Kellner ${ }^{25}$,

[...] a cultura veiculada pela mídia transformou-se numa força dominante de socialização: suas imagens e celebridades substituem a família, a escola, e a Igreja como árbitros de gosto, valor e pensamento, produzindo novos modelos de identificação e imagens vibrantes de estilo, moda e comportamento.

Bourdieu $^{26}$ trabalha com diferentes capitais na construção do gosto, os quais determinariam a distinção: econômico, social, cultural e simbólico. O capital econômico tem relação com o valor de um bem, com a mercadoria como bem simbólico; o capital social diz respeito à forma como o indivíduo se posiciona dentro de um grupo; o capital cultural se refere ao repertório que já é fruto do meio dentro do qual a pessoa cresce; por fim, o capital simbólico se constitui quando é reconhecido pelo outro em função do valor que agrega.

Assim, deve ser considerado também que, no ambiente da Internet, bem como fora do espaço virtual, há diferenças de acesso a formas de construção de conhecimento entre os jovens que são público-alvo de narrativas como Harry Potter, bem como à cultura $p o p^{27}$ em geral.

Uma questão-chave, levantada por vários autores, concerne ao seu papel no enfrentamento das desigualdades de acesso à tecnologia surgida na sociedade.
20. RICOEUR, Paul. Tempo e narrativa. Campinas: Papirus, 2010.

21. NYLUND, David. Reading Harry Potter: popular culture, queer theory and the fashioning of youth identity. Journal of Systemic Therapies, Sacramento, n. 2, p. 1324, 2007. Disponível em: $<$ http://guilfordjournals. com/doi/abs/10.1521/ jsyt.2007.26.2.13> Acesso em: 15 mar. 2017.

22. MILLER, Toby. A companion to cultural studies. Nova York: Blackwell, 2001.

23. KELLNER, Douglas. A cultura da mídia - estudos culturais: identidade e política entre o moderno e o pós-moderno. Bauru: Edusc, 2001.

24. SCHNEIDER, Marco. A dialética do gosto: informação, música e política. Rio de Janeiro: Circuito/ Faperj, 2015.

25. KELLNER, Douglas. A cultura da mídia - estudos culturais: identidade e política entre o moderno e o pós-moderno. Bauru: Edusc, 2001. p. 27.

26. BOURDIEU, Pierre. A distinção: crítica social do julgamento. Trad. Daniela Kern e Guilherme. F. Teixeira. São Paulo: Edusp; Porto Alegre: Zouk, 2007.

27. Aqui será considerada a ideia de cultura pop como cultura popular, de massa e com alto potencial de consumo. 
28. BUCKINGHAM, David. Cultura digital, educação midiática e o lugar da escolarização. Revista Educação e Realidade. v. 35, n. 3. Porto Alegre, p. 37-58, set/dez. 2010. Disponível em: <http:// seer.ufrgs.br/index.php/ educacaoerealidade/article/view/13077/10270>. Acesso em: 21 maio 2017.

29. G1. J. K. Rowling aprova Hermione negra em peça de teatro de Harry Potter. Disponível em: <http://g1.globo.com/ pop-arte/noticia/2015/12/ jk-rowling-aprova-hermione-negra-em-peca-de-teatro-de-harry-potter.html>. Acesso em: 4 jan. 2016.

30. Idem, ibidem.

31. A atriz Noma Dumezweni já venceu o prêmio Oliver, que reconhece anualmente a excelência do teatro inglês. Ver informação em: Apresentados atores que viverão Harry Potter, Hermione e Ron na peça "Harry Potter and the Cursed Child". Disponível em: <http:// revistamonet.globo.com/ Filmes/noticia/2015/12/ apresentados-atores-que-viverao-harry-potter-hermione-e-ron-na-peca-harry-potter-and-cursed-child.html>. Acesso em: 6 jan. 2016.

32. Hermione é constante alvo de preconceito ao ser chamada de "sangue ruim" por determinados personagens, com o objetivo de ofendê-la.

33. Ver 12 personagens de Harry Potter interpretados por mais de um ator. Disponível em: <http://www.adorocine$\mathrm{ma} . \mathrm{com} / \mathrm{slideshows/fil-}$ mes/slideshow-118703/7>

Acesso em: 27 out. 2016.
Acesso, neste sentido, é mais do que disponibilidade de equipamento, ou uma questão de habilidades técnicas: é também uma questão de capital cultural - a capacidade de usar formas culturais de expressão e comunicação. ${ }^{28}$

Um reflexo dessas desigualdades pode estar no fato de muitos fãs da série ignorarem, ou mesmo se mostrarem contra certos debates que dizem respeito diretamente a população negra, que tende a deter menor capital, em todas as variáveis, por uma série de obstáculos sociais.

A construção de um pensamento crítico nos jovens não abrange causas de viés político indistintamente. Há, sim, reflexão a respeito de várias questões que se inserem no debate sobre preconceito, por exemplo. Mas, ironicamente, quando entrou em questão a presença do negro na obra, muito se discutiu sobre sua validade, a qual era incontestável, uma vez que Harry Potter, embora ofereça boas reflexões sobre o preconceito racial, de modo contraditório, tem baixa presença de atores negros.

No final de 2015, houve reação preconceituosa de fãs da série à escolha de uma atriz negra para o papel de Hermione na peça Harry Potter e a criança amaldiçoada. Esse caso traz um aspecto interessante à discussão: uma parcela de fãs, embora não se possa dizer que seja a maioria, demonstrou preconceito de raça, exatamente a questão em torno da qual gira toda a história de Harry Potter.

Quando foi anunciado o trio de atores que protagonizariam a peça de teatro na Inglaterra, muitos disseram "estranhar" a escolha da atriz Noma Dumezweni para o papel da personagem Hermione, a qual nos filmes é interpretada pela atriz Emma Watson, de pele branca ${ }^{29}$. Quem questionou a escolha alegou que o estranhamento se deu pelo fato de o público já estar acostumado com uma atriz branca interpretando o papel. No entanto, os fatores que envolvem a discussão são mais complexos e preocupantes.

Originalmente, não há definição para a cor da pele da personagem nos livros da série Harry Potter. A informação foi confirmada pela autora J. K. Rowling, ao declarar que Hermione era de "olhos castanhos, cabelo crespo e muito inteligente" ${ }^{30}$, lembrando aos fãs da série que não se mencionava nada sobre cor da pele. A autora também demonstrou estar satisfeita com a escolha da atriz que, inclusive, já foi premiada no teatro inglês ${ }^{31}$. Além disso, ressalta-se que uma Hermione negra tende a representar com maior veemência o fato de a personagem sofrer preconceito na história por ser mestiça ${ }^{32}$.

Em meio a essa discussão sobre a cor da pele das atrizes, foi lembrado que, nos filmes Harry Potter e a câmara secreta e Harry Potter e o prisioneiro de Azkaban, havia a personagem chamada Lilá Brown era menos expressiva na história, com interpretação de uma atriz negra. Porém, no filme Harry Potter e o enigma do príncipe, em que a personagem ganha destaque, coincidentemente ou não, passa a ser interpretada por uma atriz branca, loira e de olhos claros ${ }^{33}$.

No entanto, há elementos na série que promovem reflexão sobre determinadas questões sociais, o que a aproxima da construção de um pensamento 
crítico e, assim, da educação, mesmo enquanto objeto de entretenimento. Segundo estudo publicado pelo Journal of Applied Social Psychology ${ }^{34}$, foi verificada maior tolerância em relação a certos estratos sociais considerados minoritários, especificamente imigrantes, homossexuais ${ }^{35}$ e refugiados, a partir do contato com a história ${ }^{36}$.

Portanto, cabe buscar alternativas para utilizar os benefícios apresentados pela obra de modo a não contribuir ainda mais para a legitimação de um processo hegemônico que é, por fim, nocivo às práticas educacionais e à formação do pensamento crítico. Ainda mais em uma sociedade que já tanto aliena as pessoas e em um momento político no Brasil que permite questionar a formação de indivíduos críticos nas escolas.

\section{CONSIDERAÇÕES FINAIS}

Nota-se que os fãs da série constroem pensamento crítico em algum grau, especialmente quando se posicionam contra pensamentos conservadores. Porém, enquanto produto midiático, a obra deve ser observada criticamente, de modo a não acabar reiterando fora da escola as práticas educacionais já existentes e que mantêm a lógica de educação apenas para o trabalho. Da mesma forma, devem ser consideradas as especificidades no acesso à informação e a diversas mídias por jovens pertencentes a diferentes grupos sociais.

Para tal, é necessário entender como se estabelece o letramento de cada grupo a partir de diferentes pautas que a obra apresenta, além de compreender como se dá o gosto que leva ao apego do público à série, percebendo que esse gosto não é somente espontâneo, embora tenha também tal característica. Esse é um ponto de partida para fazer melhor uso dos benefícios que a obra Harry Potter e outras semelhantes possam trazer enquanto práticas pedagógicas informais ${ }^{37}$. Logo, são interessantes estudos mais aprofundados, levando em conta origens e questões sobre reificação e objetivação em produtos culturais como Harry Potter, para além da questão da educação e do letramento midiático.

\section{REFERÊNCIAS BIBLIOGRÁFICAS}

BOURDIEU, Pierre. A distinção: crítica social do julgamento. Tradução de Daniela Kern e Guilherme J. F. Teixeira. São Paulo: Edusp; Porto Alegre: Zouk, 2007.

BUCKINGHAM, David. Cultura digital, educação midiática e o lugar da escolarização. Revista Educação e Realidade, Porto Alegre, v. 35, n. 3, p. 37-58, set/dez. 2010. Disponível em: <http://seer.ufrgs.br/index.php/ educacaoerealidade/article/view/13077/10270>. Acesso em: 21 maio 2017.

JENKINS, Henry. Cultura da convergência. 2. ed. São Paulo: Aleph, 2009.
34. Vários veículos de comunicação também divulgaram informações sobre o trabalho, como a Revista Galileu (disponível em: <http://revistagalileu. globo.com/Ciencia/Psicologia/noticia/2014/07/ ler-harry-potter-ensina-criancas-lutar-contra-o-preconceito1.html>); Pacific Standard (disponível em: <http://www. psmag.com/books-and-culture/harry-potter-battle-bigotry-87002>); Scientific American (disponível em: <http://www. scientificamerican.com/ article/why-everyone-should-read-harry-potter/>). Acesso em: 24 jul. 2015.

35. Tradução literal da palavra no texto original ao qual se faz a referência.

36. VEZALLI, Loris et al. The greatest magic of Harry Potter: reducing prejudice. Journal of Applied Social Psychology, Reggio Emilia, n. 45, p. 105-121, 2015. Disponível em: <http://onlinelibrary. wiley.com/doi/10.1111/ jasp.12279/pdf>. Acesso em: 22 jan. 2016.

37. JENKINS, Henry. Cultura da convergência. 2 ed. São Paulo: Aleph, 2009. 
Lendo criticamente e lendo criativamente. Matrizes, São Paulo, a. 6, n. 1, p. 11-24, jul./dez. 2012. Disponível em: <http://www.revistas.usp.br/ matrizes/article/download/ 48047/51801>. Acesso em: 22 jan. 2016.

KELLNER, Douglas. A cultura da mídia - estudos culturais: identidade e política entre o moderno e o pós-moderno. Bauru: Edusc, 2001.

MILLER, Toby. A companion to cultural studies. Nova York: Blackwell, 2001.

NYLUND, David. Reading Harry Potter: popular culture, queer theory and the fashioning of youth identity. Journal of Systemic Therapies, Sacramento, n. 2, p. 13-24, 2007. Disponível em <http://guilfordjournals.com/doi/ abs/10.1521/jsyt.2007.26.2.13>. Acesso em: 15 mar. 2017.

PUGH, Sheenagh. The democratic genre: fan fiction in a literary context. Londres: Seren, 2006.

RICOEUR, Paul. Tempo e narrativa. Campinas: Papirus, 1994.

SÁ, Simone Pereira de. Fanfictions, comunidades virtuais e cultura das interfaces. Anais do XXV Congresso Brasileiro de Ciências da Comunicação, Salvador, 1 a 5 de setembro de 2002. Disponível em: <http://www.intercom. org.br/papers/nacionais/2002/Congresso2002_Anais/2002_NP8SA.pdf>. Acesso em: 21 maio 2017.

SCHNEIDER, Marco. A dialética do gosto: informação, música e política. Rio de Janeiro: Circuito/Faperj, 2015.

SODRÉ, Muniz. Antropológica do espelho: uma teoria da comunicação linear e em rede. Petrópolis: Vozes, 2013.

VEZALLI, Loris et al. The greatest magic of Harry Potter: reducing prejudice. Journal of Applied Social Psychology, Reggio Emilia, n. 45, p. 105-121, 2015. Disponível em: <http://onlinelibrary.wiley.com/doi/10.1111/jasp.12279/ pdf>. Acesso em: 22 jan. 2016. 